\title{
Quantitative Geochemical Prediction from Spectral Measure- ments and its Application to Spatially Dispersed Spectral Data
}

Andrew Rodger ${ }^{1,}{ }^{*}$, Carsten Laukamp ${ }^{1}$

\author{
1 Mineral Resources Commonwealth Scientific and Industrial Research Organisation (CSIRO), \\ Andrew.Rodger@csiro.au, Carsten.Laukamp@csiro.au; \\ * Correspondence: Andrew.Rodger@csiro.au
}

Featured Application: Authors are encouraged to provide a concise description of the specific application or a potential application of the work. This section is not mandatory.

\begin{abstract}
The efficacy of predicting geochemical parameters with a 2-chain workflow using spectral data as the initial input is evaluated. Spectral measurements spanning the approximate 40025000nm spectral range are used to train a workflow consisting of a non-negative matrix function (NMF) step, for data reduction, and a random forest regression (RFR) to predict 8 geochemical parameters. Approximately 175000 spectra with their corresponding chemical analysis were available for training, testing and validation purposes. The samples and their spectral and chemical parameters represent 9399 drillcore. Of those, approximately 20000 spectra and their accompanying analysis were used for training and 5000 for model validation. The remaining pairwise data (150000 samples) were used for testing of the method. The data are distributed over 2 large spatial extents (980 $\mathrm{km}^{2}$ and $3025 \mathrm{~km}^{2}$ respectively) and allowed the proposed method to be tested against samples that are spatially distant from the initial training points. Global $\mathrm{R}^{2}$ scores and wt.\% RMSE on the 150000 validation samples are $\mathrm{Fe}(0.95 / 3.01), \mathrm{SiO}_{2}(0.96 / 3.77), \mathrm{Al}_{2} \mathrm{O}_{3}(0.92 / 1.27), \mathrm{TiO}(0.68 / 0.13), \mathrm{CaO}(0.89 / 0.41)$, $\mathrm{MgO}(0.87 / 0.35), \mathrm{K}_{2} \mathrm{O}(0.65 / 0.21)$ and $\mathrm{LOI}(0.90 / 1.14)$, given as Parameter( $\left.\mathrm{R}^{2} / \mathrm{RMSE}\right)$, and demonstrate that the proposed method is capable of predicting the 8 parameters and is stable enough, in the environment tested, to extend beyond the training sets initial spatial location.
\end{abstract}

Keywords: Spectral; Geochemistry; Random Forest, Regression, Whole Rock, MIR, SWIR, VNIR, NMF

\section{Introduction}

The routine collection of spectral reflectance measurements from drillcore and/or laboratory ready samples is now common enough that it is natural to assess the feasibility of using the spectral measurements for quantitative prediction. This action is already performed in various guises with the selected methodology generally based around the desired outcome.

Relatively simple spectral indices have been routinely used within the spectral remote sensing community with great success for many years [1-5] and more recently with proximal spectral sensing of drillcore samples within the exploration community [6-10]. The latter has been driven by the proliferation of hand-held and benchtop spectrometers that have successfully lowered the barrier to entry and provided a means of leveraging such data for more sophisticated qualitative and quantitative methodologies to aid in the exploration task.

Due to the ease with which spectral data can be collected, and the fast turnaround of higher order products generated from said reflectance data, it can be highly beneficial in providing a means of early confirmation and assessment of a variety of results that may aid in the exploration decision making process [11,12].

While questions pertaining to mineral identification in various mineral systems can be addressed with indices-based methods the approach used to relate the bulk, or 
volumetric, properties of a geological sample to its spectrum require more sophisticated methodologies.

Volume based assessment of geological samples is generally derived from a labbased analysis of the sample which comes with an inherent cost and turnaround time. While the cost and turnaround time of accessing results from laboratory samples are generally accounted for it does not mean that earlier access to that knowledge would not aid an explorer or decision maker. An earlier preliminary result may, for example, aid in the earlier definition of an existing economic ore body and allow preplanning prior to laboratory based confirmation. Alternatively, it may assist in the process of apportioning which samples are best suited for a deeper laboratory analysis and/or the actual sampling frequency best suited to answering the question at hand.

The use of a partial least squares [13] models for regression analysis relating to geochemical properties is well established [14-17]. These models are generally singular output models and require as many models as the number of parameters that are to be predicted. This use of random forest models [18] have been gaining popularity and applied successfully to both classification [19-21] and regression [22,23] problems. As well as proving to be easily implemented and robust they can also make multioutput predictions and therefore reduce the need for multiple models.

In this study we will investigate a methodology that uses a 2-step process to ascertain if wt. \% estimates from whole-rock geochemistry are reliably predictable from spectral measurements of drillcore samples prepared as pulps. The 2-step process makes use of a dimensionality reduction step followed by a multioutput decision tree approach to predict the wt.\% of 8 different whole-rock parameters, the majors and LOI, and its predictive effectiveness when applied to a testing set that encompasses a spatial extent extending beyond the initial training and test dataset.

\section{Materials}

The data used in the study are proprietary and are therefore subject to constraints. Namely, the spatial location of the data source cannot be provided without revealing proprietary information.

The data itself represent pulps collected from multiple drillcore which are distributed over 2 large spatial extents of approximately $360 \mathrm{~km} 2$ and $1120 \mathrm{~km} 2$ respectively. In this study a reference to drillcore sample is given to mean spectral sample as measured from a pulp. The complete dataset is comprised of 7 individual datasets that are made up of spectral measurements and whole rock geochemistry $(\mathrm{Fe}, \mathrm{SiO} 2, \mathrm{Al} 2 \mathrm{O} 3, \mathrm{TiO} 2, \mathrm{CaO}, \mathrm{MgO}$, $\mathrm{K} 2 \mathrm{O}$ and LOI).

Other variables included in the whole rock geochemistry were P, S and Mn but are not used in this study as they failed to produce a working model. The entire dataset comprises approximately $175 \mathrm{~K}$ samples (approximately 25000 per dataset) with dataset 1 randomly split into 20000 and 5000 samples for training and validation respectively. The remaining 6 datasets (approximately 150K samples) were held out for testing. Table 1 gives the summary statistics comprised of the mean, standard deviation, $50 \%$ and $75 \%$ quartiles, and the maximum value of the 7 datasets and the 8 geochemical parameters examined in the study

Table 1. The summary statistics comprised of the mean, standard deviation, $50 \%$ and $75 \%$ quartiles, and the maximum value of the 7 datasets and the 8 geochemical parameters examined in the study.

\begin{tabular}{|c|c|c|c|c|c|c|c|c|c|}
\hline & & $\mathrm{Fe}$ & $\mathrm{SiO}_{2}$ & $\mathrm{Al}_{2} \mathrm{O}_{3}$ & $\mathrm{TiO}_{2}$ & $\mathrm{CaO}$ & $\mathrm{MgO}$ & $\mathrm{K}_{2} \mathrm{O}$ & $\mathrm{LOI}$ \\
\hline Train/Val & mean & $\mathbf{4 1 . 7 0}$ & $\mathbf{2 4 . 5 3}$ & $\mathbf{4 . 9 4}$ & $\mathbf{0 . 2 3}$ & $\mathbf{1 . 3 1}$ & $\mathbf{1 . 0 5}$ & $\mathbf{0 . 2 4}$ & $\mathbf{7 . 3 4}$ \\
\hline & std & 18.67 & 21.91 & 5.98 & 0.39 & 5.17 & 3.46 & 0.73 & 7.44 \\
\hline & $50 \%$ & 43.85 & 16.16 & 2.49 & 0.08 & 0.04 & 0.09 & 0.01 & 5.68 \\
\hline & $75 \%$ & 58.74 & 44.53 & 6.48 & 0.27 & 0.09 & 0.25 & 0.05 & 8.74 \\
\hline & max & 69.15 & 98.70 & 53.38 & 8.63 & 52.47 & 22.00 & 9.36 & 84.79 \\
\hline Set 2 & mean & $\mathbf{4 1 . 1 8}$ & $\mathbf{2 5 . 8 3}$ & $\mathbf{5 . 3 2}$ & $\mathbf{0 . 2 7}$ & $\mathbf{0 . 9 8}$ & $\mathbf{0 . 8 0}$ & $\mathbf{0 . 1 7}$ & $\mathbf{7 . 2 1}$ \\
\hline
\end{tabular}




\begin{tabular}{|c|c|c|c|c|c|c|c|c|c|}
\hline & std & 17.62 & 21.95 & 6.29 & 0.42 & 4.47 & 3.05 & 0.56 & 7.05 \\
\hline & $50 \%$ & 41.74 & 18.93 & 2.71 & 0.09 & 0.04 & 0.08 & 0.01 & 5.63 \\
\hline & $75 \%$ & 57.29 & 46.14 & 7.25 & 0.34 & 0.08 & 0.19 & 0.04 & 8.94 \\
\hline & $\max$ & 69.29 & 96.51 & 55.92 & 10.10 & 39.70 & 21.50 & 12.10 & 73.82 \\
\hline \multirow[t]{5}{*}{ Set 3} & mean & 43.68 & 22.92 & 4.08 & 0.19 & 0.99 & 0.81 & 0.17 & 7.64 \\
\hline & std & 17.66 & 22.33 & 4.92 & 0.33 & 4.25 & 2.75 & 0.56 & 6.33 \\
\hline & $50 \%$ & 47.90 & 11.87 & 2.30 & 0.08 & 0.04 & 0.09 & 0.01 & 6.34 \\
\hline & $75 \%$ & 59.18 & 42.94 & 5.14 & 0.20 & 0.09 & 0.22 & 0.04 & 9.21 \\
\hline & $\max$ & 68.13 & 96.76 & 51.72 & 7.76 & 49.87 & 20.80 & 11.60 & 73.23 \\
\hline \multirow[t]{5}{*}{ Set 4} & mean & 45.66 & 23.01 & 4.78 & 0.20 & 0.11 & 0.14 & 0.12 & 5.83 \\
\hline & std & 16.12 & 20.52 & 5.70 & 0.31 & 0.96 & 0.57 & 0.44 & 3.05 \\
\hline & $50 \%$ & 48.99 & 15.94 & 2.50 & 0.08 & 0.03 & 0.06 & 0.01 & 5.36 \\
\hline & $75 \%$ & 59.56 & 40.11 & 6.07 & 0.24 & 0.05 & 0.10 & 0.03 & 7.81 \\
\hline & $\max$ & 68.77 & 97.65 & 39.19 & 6.84 & 48.73 & 18.50 & 7.65 & 42.96 \\
\hline \multirow[t]{5}{*}{ Set 5} & mean & 43.36 & 25.37 & 4.57 & 0.22 & 0.34 & 0.32 & 0.13 & 6.44 \\
\hline & std & 15.68 & 21.05 & 5.42 & 0.33 & 2.68 & 1.76 & 0.41 & 4.61 \\
\hline & $50 \%$ & 44.33 & 19.45 & 2.36 & 0.08 & 0.01 & 0.05 & 0.01 & 5.64 \\
\hline & $75 \%$ & 57.46 & 44.26 & 6.29 & 0.29 & 0.03 & 0.11 & 0.03 & 8.43 \\
\hline & $\max$ & 67.32 & 97.73 & 51.14 & 5.96 & 40.53 & 21.00 & 6.85 & 47.01 \\
\hline \multirow[t]{5}{*}{ Set 6} & mean & 43.00 & 23.52 & 5.67 & 0.31 & 0.48 & 0.59 & 0.24 & 6.85 \\
\hline & std & 17.34 & 21.43 & 6.16 & 0.48 & 2.76 & 2.11 & 0.67 & 4.83 \\
\hline & $50 \%$ & 45.74 & 14.59 & 3.15 & 0.12 & 0.02 & 0.06 & 0.01 & 6.10 \\
\hline & $75 \%$ & 58.11 & 43.35 & 8.75 & 0.46 & 0.06 & 0.21 & 0.10 & 9.09 \\
\hline & $\max$ & 69.49 & 96.89 & 51.29 & 25.20 & 42.55 & 20.70 & 6.49 & 46.89 \\
\hline \multirow[t]{5}{*}{ Set 7} & mean & 41.25 & 26.53 & 5.32 & 0.28 & 0.56 & 0.71 & 0.28 & 6.41 \\
\hline & std & 17.46 & 21.85 & 6.14 & 0.45 & 2.96 & 2.29 & 0.74 & 5.33 \\
\hline & $50 \%$ & 41.30 & 20.73 & 2.70 & 0.10 & 0.03 & 0.10 & 0.01 & 5.40 \\
\hline & $75 \%$ & 56.80 & 46.11 & 7.82 & 0.36 & 0.09 & 0.34 & 0.08 & 8.80 \\
\hline & $\max$ & 69.49 & 97.66 & 48.03 & 8.63 & 37.42 & 20.40 & 7.07 & 46.76 \\
\hline
\end{tabular}

The spectral data collected from any given pulp sample was via 2 different spectral instruments. The first is the HyLogger [24-26] which collected data in the 350-2500nm spectral range and whose spectral outputs are given with a $4 \mathrm{~nm}$ sampling interval, and the second, a Fourier Transform Interferometer for spectral collection from 2000nm$25000 \mathrm{~nm}$ with a spectral sampling interval of $3.857 \mathrm{~cm}-1$. To create a single spectrum the FTIR data from 2000-2500nm was disregarded and the remaining spectral signal appended to the HyLogger spectrum.

\section{Methods}

The task is to assess the feasibility of predicting whole rock geochemistry parameters with spectral data used as the driving input to the model/s. The combined HyLogger and FTIR spectral data comprise 1476 spectral bands. To reduce computational overhead and to reduce the dimensionality of the spectra we firstly use a non-negative matrix factorisation (NMF) model [27] and follow that with a random forest regression (RFR) model [18] to make our prediction. The model implementations for the NMF and RFR are provided by the python scikit-learn library [28].

\subsection{NMF}

The NMF model is a method of representing data as a linear representation using non-negativity constraints. The imposed non-negative constraint leads to a part-based representation that allows only additive, not subtractive, combinations of the original data 
$[27,29]$. Using the NMF in the first step allows us to reduce the dimensionality of the input data to manageable levels that can be used as input to the regression model.

In the 2-step process used herein we firstly reduce the spectral data to a series of components with an NMF model where the components are the representation of the additive parts comprising the training signals. Due to the non-negative nature of the components they can have a physically interpretable correspondence [30,31], or when the components are predefined such that the components represent spectral endmembers the parts based weights returned are indicative of the proportions of those endmembers and hence can be used in a linear spectral unmixing [32-36].

The 20000 spectra selected for training were firstly used in the construction of a series of NMF models where the number of components used in each model differed. e.g. 5, 10, $15, \ldots, 30$ components. In this study a reconstruction $\mathrm{R}^{2}$ score of 0.99 was sought on the transformed spectra and inverse transformed NMF values. By this it means that a given NMF model is generated for a given number of components and the 5000 validation spectra transformed into the NMF space and the inverse transformed applied, and the resulting spectra compared to the original testing spectra and the $\mathrm{R}^{2}$ calculated. The high valued constraint on the $\mathrm{R}^{2}$ of the reconstruction is set so we are confident that the components are representative of the measured spectra and are a compressed version of the original dataset. In this study 25 components satisfied the criteria of a 0.99 R2. The NMF model was then established for 25 components and saved so it could be used to transform any of the remaining spectra.

Although it isn't explored further, and as noted earlier, the 25 components can be considered as spectral end-members of the training set [32-34,37] where the components, in this case, are a representation of spectral endmembers of the dataset and the weighting values returned in the transform the proportion of each endmember required to produce the measured spectrum. In terms of physical size on disk the trained NMF model occupies approximately $300 \mathrm{~KB}$ of space.

\subsection{RFR}

With a dimensionality step in place via an NMF model the resulting 25 weighting values output for a given sample are used as the input features to the RFR model to provide the actual prediction value. In a regression scenario random forests, or random decision forests, are an ensemble method that use a collection of decision tress to output the mean prediction of the individual trees [18]. The benefit of using random forests is they are generally considered robust and self-correcting so can reduce the overfitting often observed in individual decision trees [18,38].

While several implementation parameters can be used to construct an RFR model we have opted to use the defaults as set in the scikit-learn library except for the maximum depth of the decision trees. In the final RFR model the maximum depth of an individual tree was set at 16 .

The latter value was determined by increasing the maximum depth of the RFR model until the $\mathrm{R}^{2}$ score of the predictors was found to be minimally different to an RFR model with an unbounded maximum depth on the decision trees. The resulting RFR model was then trained and validated with the 20000 and 5000 spectral samples respectively and saved for future use with the remaining validation data. The physical size of the RFR model on disk is $130 \mathrm{MB}$.

In summary the application of the 2-step methodology after training and validation is as follows:

1. Set any spectral reflectance values that are less than zero to zero (potential measurement errors). This is a requirement since the NMF cannot work with negative inputs.

2. Transform the Nx1476 individual spectra via the precomputed NMF model to the Nx25 sample space, where $\mathrm{N}$ is the number of spectral samples.

3. Input the Nx25 NMF transformed spectra into the precomputed RFR model and retrieve the estimated parameter values for $\mathrm{Fe}, \mathrm{SiO}_{2}, \mathrm{Al}_{2} \mathrm{O}_{3}, \mathrm{TiO}, \mathrm{CaO}, \mathrm{MgO}, \mathrm{K}_{2} \mathrm{O}$ and LOI. 


\section{Results}

The results contained herein are split into 3 subsections. Namely, spectral, global, and downhole. Each subsection focuses on an aspect of the data and/or its relevance to the results. The spectral subsection will look at spectra associated with the 8 geochemical parameters and the potential minerals associated with said parameters. The global subsection looks at the performance of the prediction model as it applies to the entire collection of validation data. Lastly, the downhole subsection presents a downhole comparison of predicted results against the measured response of 4 drillcore.

\subsection{Spectral}

To gauge the potential differences in the spectra associated with a given element, validation dataset four was used to retrieve the spectra corresponding to each of the 8 geochemical parameters being at their maximum values. These spectra are shown in Figure 1 where the parameter and value of the maximum for the spectral sample is provided in the legend. To distinguish between the absorptions more easily across the 400-25000nm spectral range two separate plots are shown. The upper plot covers the 400-6000nm and the lower plot the $6000-25000 \mathrm{~nm}$ spectral region. These spectra are not presented to provide an in-depth analysis of the full suite of potential minerals that might be encountered but rather to ascertain if the mineral types are at least consistent with what might be observed when the given geochemical parameter is at a maximum.
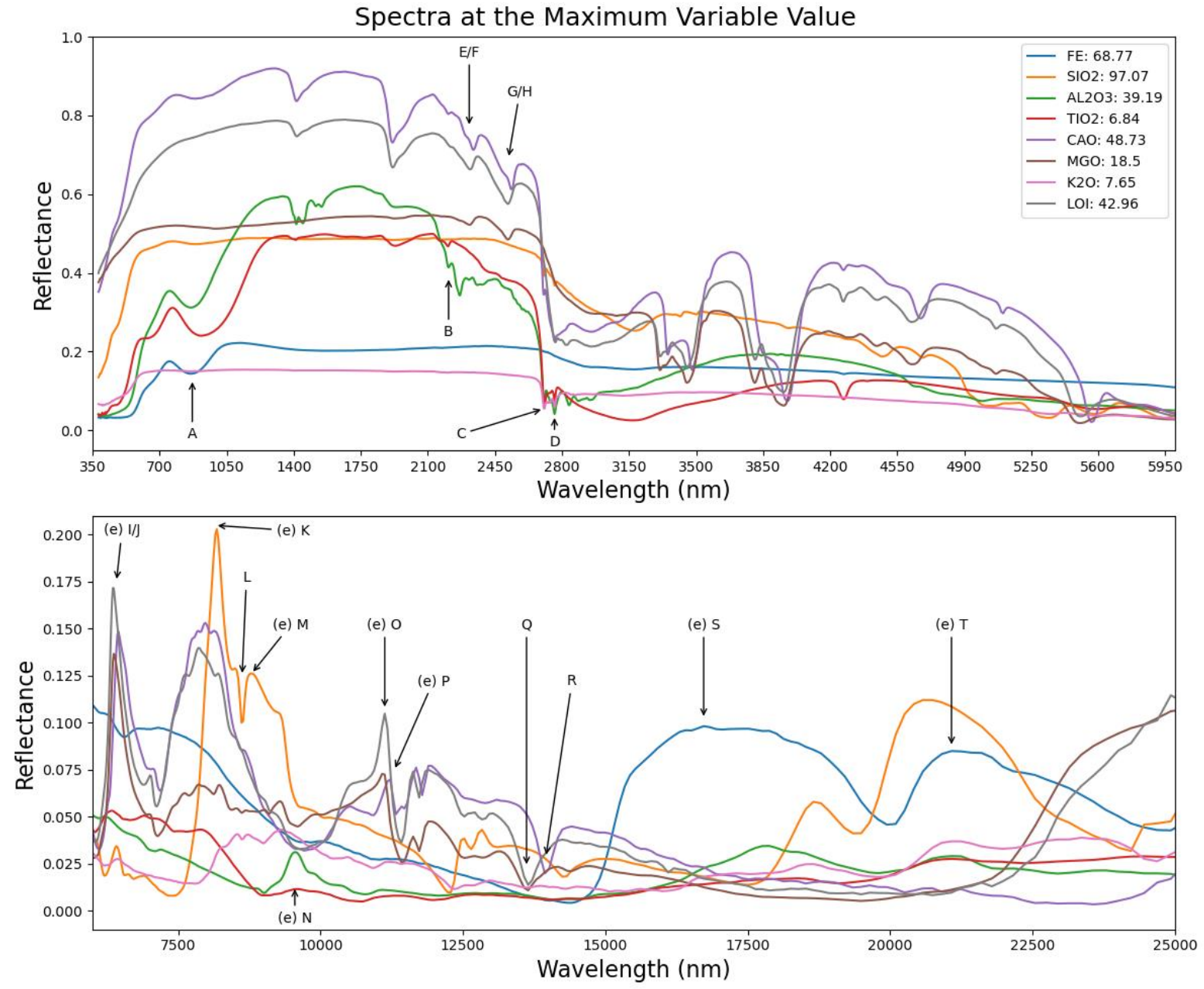

Figure 1. Indicative spectra selected from dataset 4 corresponding to the maximum value of a given geochemical parameters. The spectra are indicators only of the potential differences in reflectance that might be associated with a given parameter. It is expected, and confirmed, that certain whole-rock parameters will be consistent with given mineral assemblages. Complementary to this 
figure is Table 2 which provides a summary of some of the major absorption/emission features of minerals present in the study area and noted within the spectra.

Complementary to Figure 1 is Table 2 which provides a summary of some of the major absorption/emission features of minerals present in the study area. It is noted that respective absorption bands can be present in minerals that are not listed in table. The lower and upper wavelength positions are only given for absorption bands where related compositional changes occur otherwise, an estimated central location is provided.

Table 2. A summary of some of the major absorption/emission features of minerals present in the study area. It is noted that respective absorption bands can be present in minerals that are not listed in table. The lower and upper wavelength positions are only given for absorption bands where related compositional changes occur otherwise, an estimated central location is provided.

\begin{tabular}{|c|c|c|c|c|}
\hline Label & $\begin{array}{c}\text { Dominant mineral } \\
\text { group compo- } \\
\text { nent/Group }\end{array}$ & Assignment & Literature & $\mathrm{nm} / \mathrm{cm}-1$ \\
\hline A & iron oxide/Hematite & $\begin{array}{c}\mathrm{Fe} 3+\mathrm{CFA}(6 \mathrm{~A} 1> \\
4 \mathrm{~T} 1)\end{array}$ & [39] & $877 / 11403$ \\
\hline $\mathrm{B}$ & kaolin group/Kaolin & $\mathrm{n}+\mathrm{dAl} 2 \mathrm{OHi}$ & {$[40]$} & $2209 / 4527$ \\
\hline $\mathrm{C}$ & kaolin group/Kaolin & nAl2OHo & {$[40]$} & $2705 / 3697$ \\
\hline $\mathrm{D}$ & kaolin group/Kaolin & $\mathrm{nAl} 2 \mathrm{OHi}$ & {$[40]$} & $2761 / 3622$ \\
\hline $\mathrm{E}$ & $\begin{array}{l}\text { Mg-rich Calcium car- } \\
\text { bonate/Dolomite }\end{array}$ & $3 n 3 \mathrm{CO} 3$ & [41] & $\begin{array}{c}2312-2323 / 4325- \\
4305\end{array}$ \\
\hline $\mathrm{F}$ & $\begin{array}{c}\text { Calcium car- } \\
\text { bonate/Calcite }\end{array}$ & $3 \mathrm{n} 3 \mathrm{CO} 3$ & [41] & $2340 / 4237$ \\
\hline G & $\begin{array}{l}\text { Mg-rich Calcium car- } \\
\text { bonate/Dolomite }\end{array}$ & $2 \mathrm{n} 3+\mathrm{n} 1$ & [41] & $\begin{array}{c}2505-2518 / 3992- \\
3971 \\
\end{array}$ \\
\hline $\mathrm{H}$ & $\begin{array}{c}\text { Calcium car- } \\
\text { bonate/Calcite }\end{array}$ & $2 n 3+n 1$ & [41] & $\begin{array}{c}2530-2541 / 3953- \\
3935 \\
\end{array}$ \\
\hline I & $\begin{array}{c}\text { Mg-rich Calcium car- } \\
\text { bonate/Magnesite }\end{array}$ & "n3peak"CO3 & [7] & $6405 / 1561$ \\
\hline $\mathrm{J}$ & $\begin{array}{c}\text { Calcium car- } \\
\text { bonate/Dolomite }\end{array}$ & "n3peak"CO3 & {$[7]$} & $6490 / 1541$ \\
\hline $\mathrm{K}$ & Quartz/Quartz & $\mathrm{n}(\mathrm{Si}-\mathrm{O}-\mathrm{Si})$ & [42] & $8150 / 1227$ \\
\hline $\mathrm{L}$ & quartz/Quartz & $\mathrm{n}(\mathrm{Si}-\mathrm{O}-\mathrm{Si})$ & {$[42]$} & $8598 / 1163$ \\
\hline M & $\begin{array}{c}\text { Quartz/Vitreous Sil- } \\
\text { ica }\end{array}$ & $\mathrm{n}(\mathrm{Si}-\mathrm{O}-\mathrm{Si})$ & [43] & $9025 / 1108$ \\
\hline $\mathrm{N}$ & $\begin{array}{l}\text { kaolin group/Kaolin } \\
\text { Group }\end{array}$ & nSi-O & [44] & $9891 / 1011$ \\
\hline $\mathrm{O}$ & $\begin{array}{c}\text { Mg-rich Calcium car- } \\
\text { bonate/Magnesite }\end{array}$ & "n2peak"CO3 & [7] & $11058 / 904$ \\
\hline $\mathrm{P}$ & $\begin{array}{c}\text { Calcium car- } \\
\text { bonate/Dolomite }\end{array}$ & "n2peak"CO3 & [7] & $11236 / 890$ \\
\hline Q & $\begin{array}{l}\text { Mg-rich Calcium car- } \\
\text { bonate/Ankerite }\end{array}$ & "n4trough"CO3 & [7] & $13656 / 732$ \\
\hline $\mathrm{R}$ & $\begin{array}{l}\text { Calcium car- } \\
\text { bonate/Calcite }\end{array}$ & "n4trough"CO3 & [7] & $13942 / 717$ \\
\hline$S$ & iron oxide/Hematite & $\begin{array}{c}\text { Fe-O lattice vi- } \\
\text { bration }\end{array}$ & [45] & $16393 / 610$ \\
\hline $\mathrm{T}$ & iron oxide/Hematite & $\begin{array}{c}\text { Fe-O lattice vi- } \\
\text { bration }\end{array}$ & [45] & $22026 / 454$ \\
\hline
\end{tabular}


In Figure 1 the spectra named $\mathrm{Fe}, \mathrm{Al}_{2} \mathrm{O}_{3}$ and $\mathrm{TiO}_{2}$ display iron oxide absorptions that are characterised by crystal field interactions around $900 \mathrm{~nm}[46,47]$ and are indicative of hematite and goethite. The spectrum associated with the greatest amount of Fe in this case does not appear to have the greatest $900 \mathrm{~nm}$ absorption depth, as compared to the $\mathrm{Al}_{2} \mathrm{O}_{3}$ and $\mathrm{TiO}_{2}$ spectra, and is seemingly free from indicative kaolin group absorptions located at 2206nm [40,47] and 2705nm [40] and 2761nm [40] which are present in the $\mathrm{Al}_{2} \mathrm{O}_{3}$ and $\mathrm{TiO}_{2}$ spectra. The Fe spectrum in this case, and because of the lack of other mineral absorptions, is probably a relatively pure Fe sample.

The $\mathrm{CaO}$ and $\mathrm{MgO}$ (and the sample with the highest $\mathrm{LOI}$ ) samples are consistent with carbonates. Absorption features associated with carbonates are observed at approximately $2300 \mathrm{~nm}[41,48], 2500 \mathrm{~nm}[41], 3500 \mathrm{~nm}, 4000 \mathrm{~nm}, 4600 \mathrm{~nm}$ and $6400-6500 \mathrm{~nm}$ [7]. Calcium dominated carbonates, such as calcite, have absorptions at longer wavelengths in the $2300 \mathrm{~nm}$ and $2500 \mathrm{~nm}$ spectral regions as opposed to those carbonates, such as siderite or magnesite, where $\mathrm{Fe}$ or $\mathrm{Mg}$ replaces the $\mathrm{Ca}$, and the absorption features shift to shorter wavelengths [48-50].

As noted, the $\mathrm{Al}_{2} \mathrm{O}_{3}$ spectrum display several absorptions commonly associated with kaolinite but also contain jarosite as defined by a distinct absorption at 2260nm [51]. The sample associated with the greatest $\mathrm{TiO}_{2}$ has weak kaolin group absorptions at $2160 \mathrm{~nm}$ and $2200 \mathrm{~nm}$ and around $2700 \mathrm{~nm}$.

The spectrum relating to the highest valued $\mathrm{SiO}_{2}$ is devoid of discernible absorption features in the VNIR/SWIR but is distinguishable as a quartz sample by the notable peaks located at approximately $8500 \mathrm{~nm}, 9000 \mathrm{~nm}, 12500 \mathrm{~nm}$ and $12800 \mathrm{~nm}[42,43]$. Lastly, the spectrum associated with the highest $\mathrm{K}_{2} \mathrm{O}$ value is almost free of any discernible absorption features with the exception being kaolin group absorptions around $2700 \mathrm{~nm}$. In this case the SWIR absorptions around 2200nm that are also associated with the kaolin group are not discernible.

\subsection{Global}

Table 3 and Figures 2-5 summarise the results of the 2-step workflow, namely NMFRFR referred to earlier. In Table 3, three separate values are referred to, namely the $\mathrm{R}^{2}$, the RMSE and the standard deviation of the RMSE. Column 1 names the dataset in question and lists the number of drillholes that are present in each dataset. Any row that refers to the training dataset are the values as returned by applying the models to the 5000 validation samples while the remaining datasets are the results of applying the models to the unseen testing datasets. The results listed for the "Training" dataset are those values as returned by the validation set (5000 samples) for the RFR model trained on the training set (20000 samples). All global averages given are the averages for the 6 testing datasets (given as Set2-Set7). In Figures 3 and 5 the results do not include any values from the training/validation dataset and are only comprised of results from testing datasets (Set2Set7). 


\section{Global $R^{2}$ Summary}

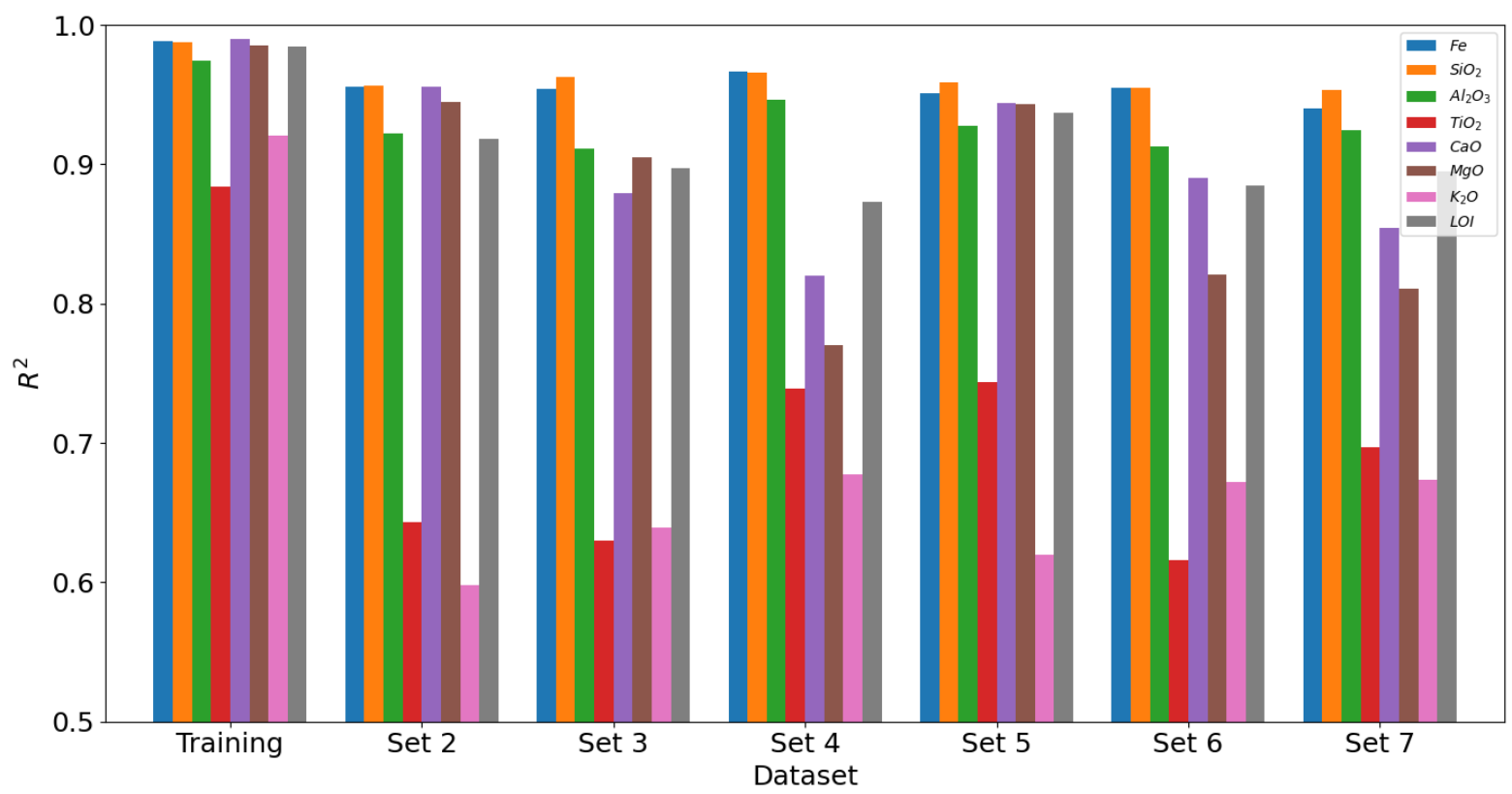

Figure 2. The calculated $\mathrm{R}^{2}$ scores for each of the 6 testing datasets (sets 2-7) and the training and validation dataset (simply given as Training) for the 8 whole-rock parameters modeled. The training and validation data return high $\mathrm{R}^{2}$ scores overall which are found to generally decrease when the model was applied to the testing datasets. The reduction in the overall R2 scores was most pronounced in the $\mathrm{TiO}_{2}, \mathrm{CaO}, \mathrm{MgO}$ and $\mathrm{K}_{2} \mathrm{O}$ parameters whose values low for most of the data and are considered as consisting of primarily background (refer to Figure 4).
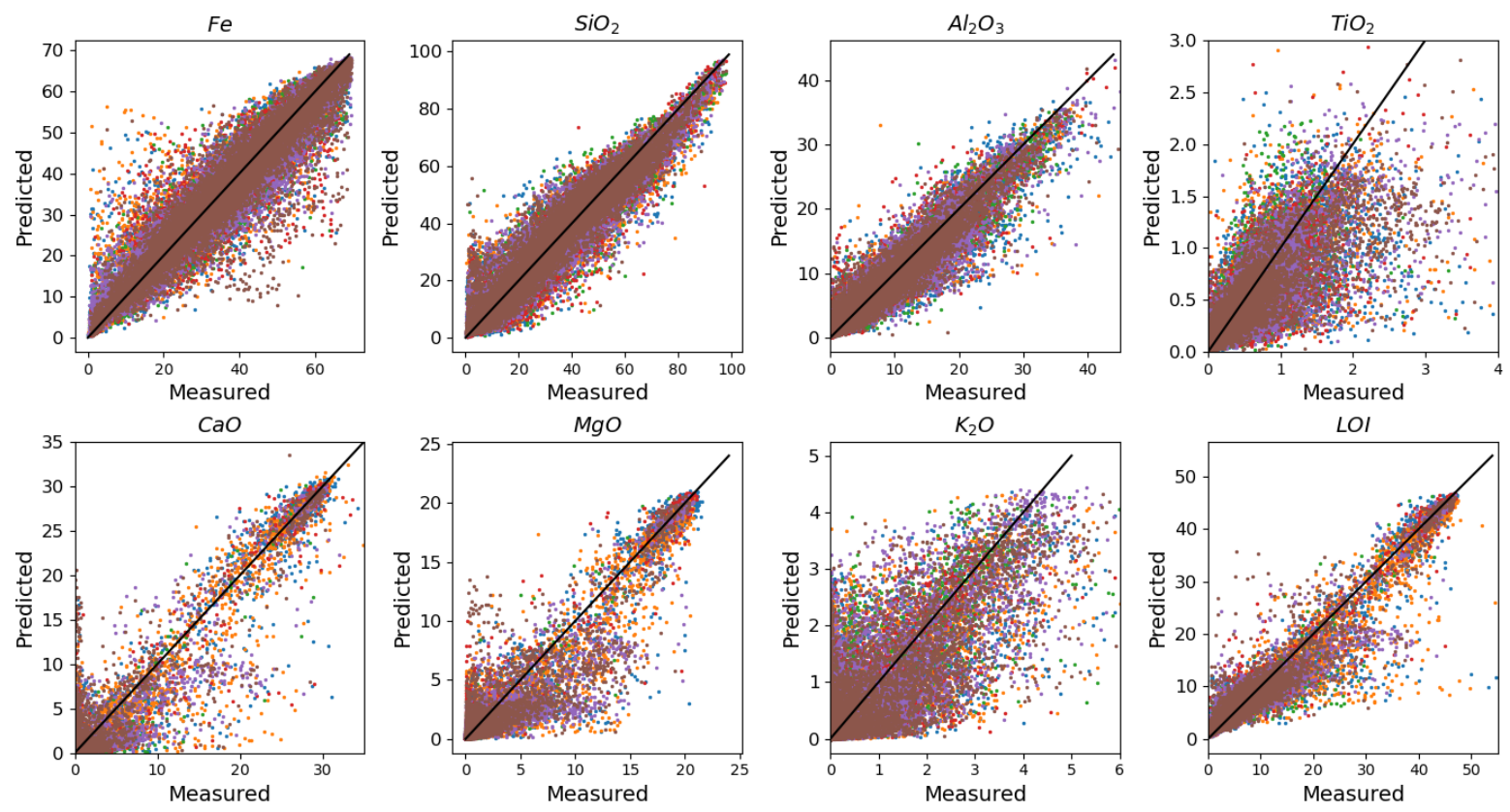

Figure 3. Measured whole-rock parameters versus the predicted value for the 8 geocheimical parameters used (wt.\%). Each plot shows the combined measured versus predicted for the 6 valiation datasets only. The 1-to-1 line is shown in black for each plot. While $\mathrm{CaO}$ and $\mathrm{MgO}$ show what appear to be appreciable ranges the bimodal nature of the values is also observed with the bulk of the being primarily distributed around the origin i.e. background values (refer to Figure 4). 


\section{Empirical Cumulative Distribution Function}
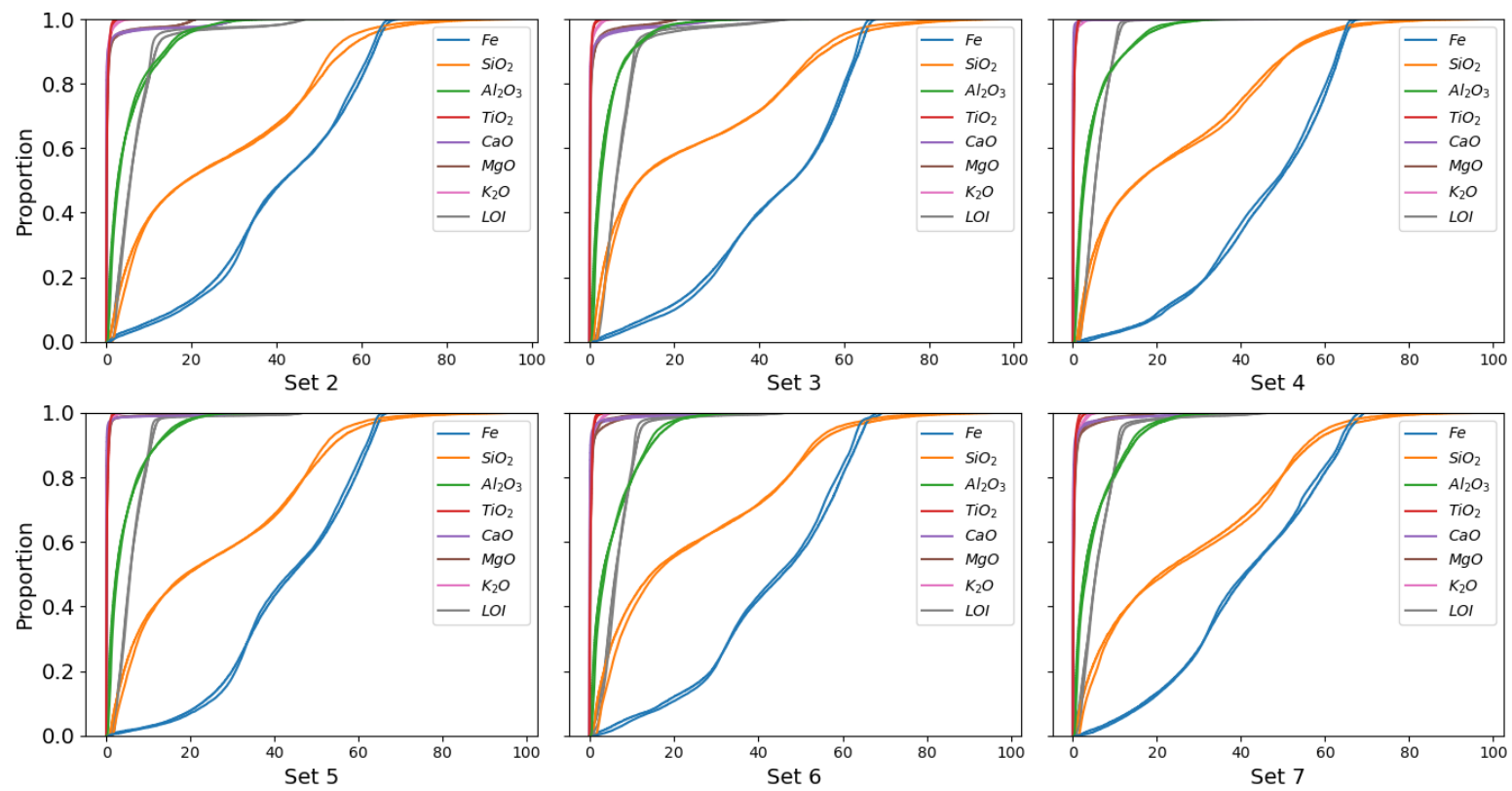

Figure 4. The empirical cumalative distribution of the 8 whole-rock geochemical parameters for the 6 validation datasets (sets 2-7) and the predicted values as returned by the proposed method. A succesful prediction over a given dataset should produce a distribution that is the same as the actual distribution. Generally small departures are noted and would indicate that the model is accurately reproducing the true distribution and values. It is noted that the distributions for $\mathrm{TiO}_{2}, \mathrm{CaO}, \mathrm{MgO}$ and $\mathrm{K}_{2} \mathrm{O}$ show the range of values for these parameters is exteremely small and primarily confined to background.
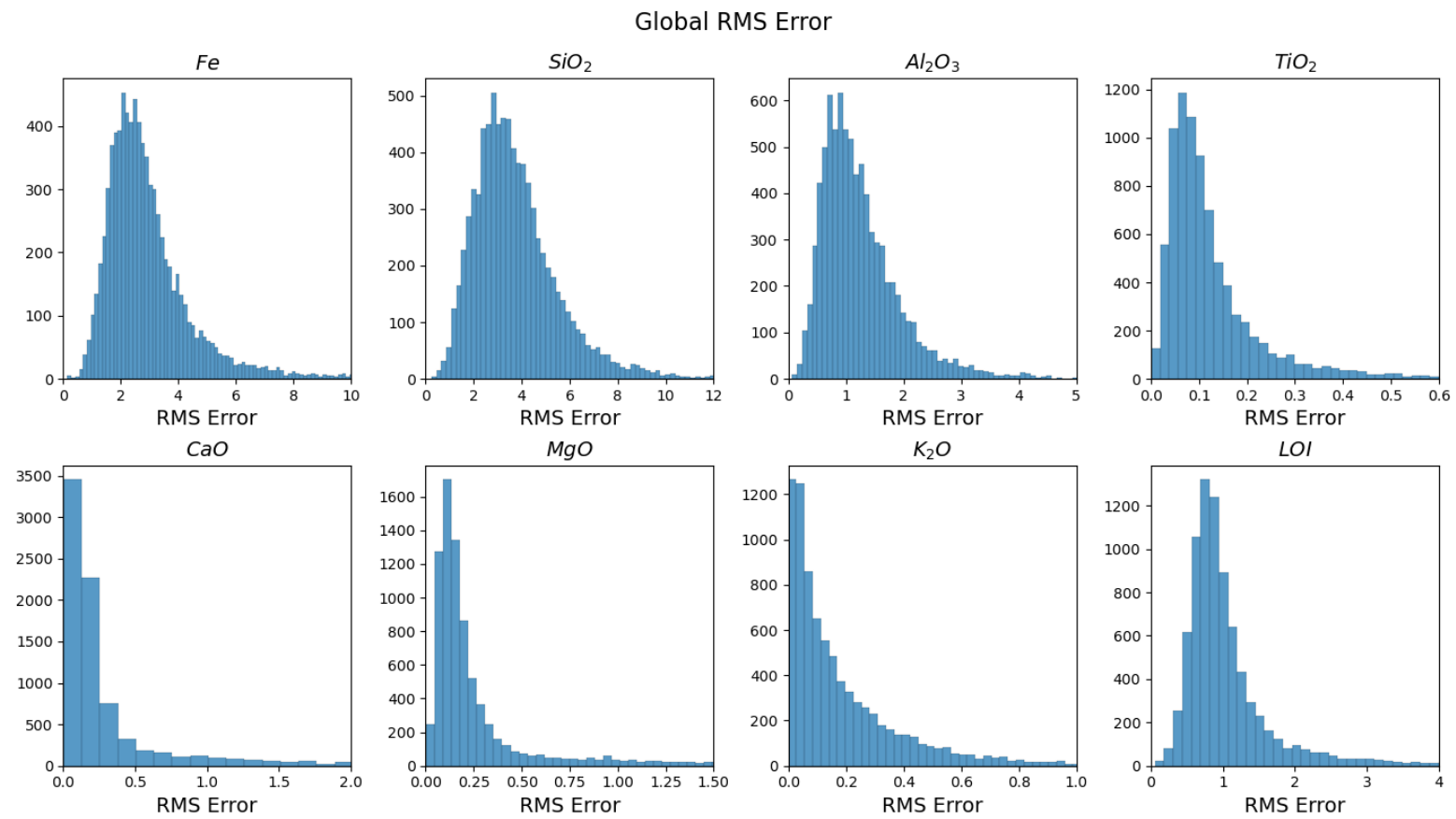

Figure 5. The RMSE (wt.\%) distribution of the 8 whole-rock geochemistry parameters as calculated from the 6 validation datasets. In this case the RMSE is that reported on a per-drillhole basis so the spread of potential RMSE can be evaluated. While the $\mathrm{R}^{2}$ scores (Figure 1) for $\mathrm{TiO}_{2}, \mathrm{CaO}, \mathrm{MgO}$ and $\mathrm{K}_{2} \mathrm{O}$ were found to generally be smaller than the other four majors the small RMSE and known distribution still indicate a fairly successful modeling.

Table 1. The $\mathrm{R}^{2}$ score, RMSE and standard deviation of the RMSE for the 8 whole-rock geochemical parameters used for training and validation data and the 6 individual test data sets. The number of drillcore for a given dataset are given in the first column 
with each dataset comprising approximately 25000 samples. The results are calculated on a per-dataset basis and represent global results per dataset.

\begin{tabular}{|c|c|c|c|c|c|c|c|c|c|}
\hline Dataset & & $\mathrm{Fe}$ & $\mathrm{SiO}_{2}$ & $\mathrm{Al}_{2} \mathrm{O}_{3}$ & $\mathrm{TiO}_{2}$ & $\mathrm{CaO}$ & $\mathrm{MgO}$ & $\mathrm{K} 2 \mathrm{O}$ & LOI \\
\hline Train/Val: 1185 & $\mathrm{R}^{2}$ & 0.99 & 0.99 & 0.97 & 0.88 & 0.99 & 0.99 & 0.92 & 0.98 \\
\hline Set 2: 1603 & & 0.96 & 0.96 & 0.92 & 0.64 & 0.96 & 0.95 & 0.60 & 0.92 \\
\hline Set 3: 1292 & & 0.95 & 0.96 & 0.91 & 0.63 & 0.88 & 0.91 & 0.64 & 0.90 \\
\hline Set 4: 1087 & & 0.97 & 0.97 & 0.95 & 0.74 & 0.82 & 0.77 & 0.68 & 0.87 \\
\hline Set 5: 1620 & & 0.95 & 0.96 & 0.93 & 0.74 & 0.94 & 0.94 & 0.62 & 0.94 \\
\hline Set 6: 1542 & & 0.95 & 0.96 & 0.91 & 0.62 & 0.89 & 0.82 & 0.67 & 0.88 \\
\hline Set 7: 1070 & & 0.94 & 0.95 & 0.92 & 0.70 & 0.85 & 0.81 & 0.67 & 0.89 \\
\hline & Average & 0.95 & 0.96 & 0.92 & 0.68 & 0.89 & 0.87 & 0.65 & 0.90 \\
\hline Train/Val: 1185 & RMSE & 1.74 & 2.13 & 0.82 & 0.09 & 0.29 & 0.23 & 0.13 & 0.78 \\
\hline Set 2: 1603 & & 3.00 & 3.83 & 1.29 & 0.15 & 0.41 & 0.35 & 0.18 & 1.16 \\
\hline Set 3: 1292 & & 3.21 & 3.84 & 1.25 & 0.13 & 0.74 & 0.55 & 0.25 & 1.42 \\
\hline Set 4: 1087 & & 2.69 & 3.46 & 1.23 & 0.12 & 0.23 & 0.19 & 0.19 & 0.96 \\
\hline Set 5: 1620 & & 2.88 & 3.74 & 1.15 & 0.12 & 0.27 & 0.23 & 0.15 & 0.95 \\
\hline Set 6: 1542 & & 2.91 & 3.71 & 1.30 & 0.13 & 0.32 & 0.32 & 0.18 & 1.09 \\
\hline Set 7: 1070 & & 3.38 & 4.05 & 1.41 & 0.16 & 0.53 & 0.47 & 0.29 & 1.24 \\
\hline & Average & 3.01 & 3.77 & 1.27 & 0.13 & 0.41 & 0.35 & 0.21 & 1.14 \\
\hline Train/Val: 1185 & Sdev RMSE & 0.99 & 1.21 & 0.42 & 0.10 & 0.43 & 0.32 & 0.16 & 0.49 \\
\hline Set 2: 1603 & & 1.62 & 1.95 & 0.86 & 0.15 & 0.71 & 0.53 & 0.27 & 1.20 \\
\hline Set 3: 1292 & & 2.01 & 1.99 & 0.71 & 0.14 & 1.36 & 0.69 & 0.27 & 1.39 \\
\hline Set 4: 1087 & & 1.26 & 1.65 & 0.55 & 0.09 & 0.40 & 0.22 & 0.19 & 0.54 \\
\hline Set 5: 1620 & & 1.68 & 1.86 & 0.68 & 0.11 & 0.51 & 0.31 & 0.16 & 0.56 \\
\hline Set 6: 1542 & & 1.39 & 1.72 & 0.82 & 0.14 & 0.61 & 0.56 & 0.23 & 0.76 \\
\hline Set 7: 1070 & & 1.93 & 1.95 & 0.84 & 0.16 & 0.78 & 0.66 & 0.29 & 0.92 \\
\hline & & 1.65 & 1.85 & 0.74 & 0.13 & 0.73 & 0.49 & 0.24 & 0.89 \\
\hline
\end{tabular}

An examination of the training/validation data $\mathrm{R}^{2}$ scores in Table 3 and Figure 2 to that of Set2-Set7 shows the $\mathrm{R}^{2}$ is generally maintained in the testing datasets but does decrease, notably for $\mathrm{TiO}_{2}$ and $\mathrm{K}_{2} \mathrm{O}$, compared to the $\mathrm{R}^{2}$ for the training/validation data. This is not wholly unexpected as the spatial locations of the training/validation data are in some cases many tens of kilometres removed from the testing cases.

Figure 3 shows the measured versus predicted values for the 6 validation data sets with the black line in each plot representing the 1-to-1 line. Specifically, the range of values for $\mathrm{TiO}_{2}$ and $\mathrm{K}_{2} \mathrm{O}$ are seen to be small as compared to the other parameters with the bulk of the $\mathrm{TiO}_{2}$ and $\mathrm{K}_{2} \mathrm{O}$ heavily clustered near the origin. The lack of defining range for these two parameters would seem a likely contributing factor to their decreased $\mathrm{R}^{2}$ values. $\mathrm{CaO}$, $\mathrm{MgO}$ and the LOI have a level of bimodal distribution (see Figure 3) and while they also are heavily distributed near the origin the bimodality most likely helps to extend the range and provide clearer paths for the decision trees within the RFR. The bimodal distribution of the LOI, which corresponds with the $\mathrm{MgO}$ and $\mathrm{CaO}$ distributions, aligns with the spectral examples given in Figure 1 where the spectrum from dataset 4 that corresponding to the greatest LOI value is a carbonate dominated spectrum like the $\mathrm{MgO}$ and $\mathrm{CaO}$ spectra.

Figure 4 shows the estimated cumulative distribution function for the 6 validation datasets and the 8 geochemical parameters. This plot (estimated from kernel density estimators) allows a comparison of the predicted value distributions to the measured. A successful prediction for a given dataset should show the same distribution without major deviations. In general, the distributions follow each other for a given dataset and parameter indicating that the combined NMF-RFR model is working reasonably well. 
Figure 5 presents the distribution of RMSE for each of the predicted parameters over the 6 validation datasets. No distinction in this figure is made between the 6 datasets and the results are therefore global. In most cases the central RMSE is small compared to the overall range of values for a given parameter. However, and as noted previously, the clustering of values for $\mathrm{TiO}_{2}$ and $\mathrm{K}_{2} \mathrm{O}$ around the origin implies the RMSE for these parameters is relatively larger than their counterparts.

\subsection{Downhole}

Lastly, and shown in Figure 6 are the downhole predicted and measured values for $\mathrm{Fe}, \mathrm{SiO}_{2}, \mathrm{Al}_{2} \mathrm{O}_{3}$ and $\mathrm{LOI}$ of 4 drillcore. The drillcore shown are not from any one dataset and were selected based on their length (randomly selected from all drillcore that had greater than 150 entries) to show the ability of the model. The other 4 geochemical parameters are not shown since the scale of the plots reduces those traces to lines just above zero.
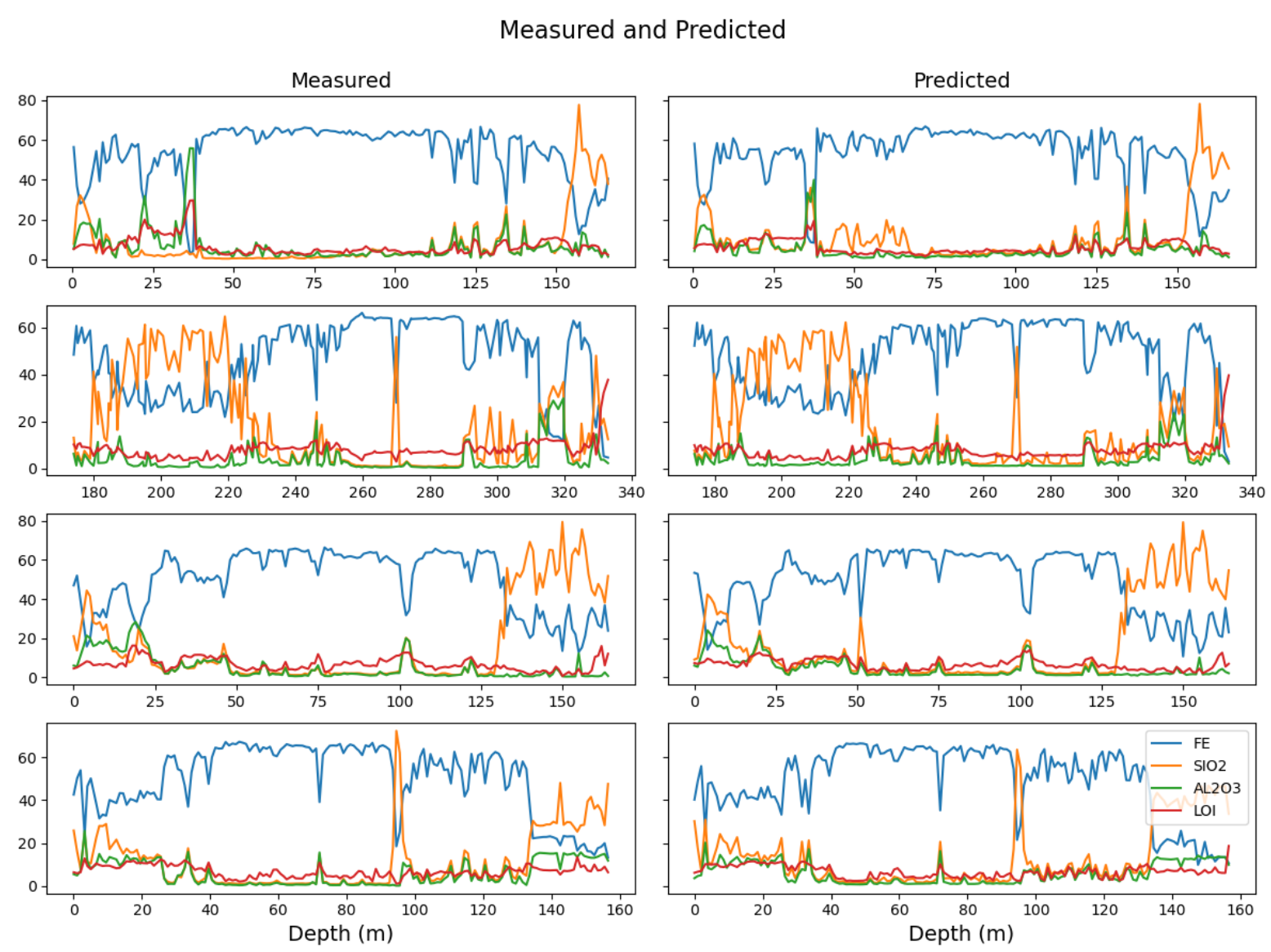

Figure 6. The measured and predicted downhole values for $\mathrm{Fe}, \mathrm{SiO}_{2}, \mathrm{Al}_{2} \mathrm{O}_{3}$ and $\mathrm{LOI}$ of 4 randomly selected drillcore where the length of the drillcore comprised greater than 150 entries. The other whole-rock geochemistry parameters are not shown due to the values being comprised of background only which only appear as singular valued traces along $y=0$. Overall a good corespondence between the predicted and measured values is observed with generally minor deviations noted.

The measured values are shown on the left-hand side and the predicted values on the right. The y-axis on all measured-predicted pairs is the same for ease of comparison. The performance of the model is generally observed to be good and matches the measured values well. Some discrepancies can be found but overall, the geochemical parameters as predicted from the spectral input could most certainly be used to ascertain the downhole distribution and value of said parameters.

This section may be divided by subheadings. It should provide a concise and precise description of the experimental results, their interpretation, as well as the experimental conclusions that can be drawn. 


\subsection{Discussion \& Conclusions}

The aim of this study was to ascertain if geochemical parameters could be predicted from spectral measurements. The spectral measurements in this study have a 1-to- 1 correspondence with whole-rock geochemistry and provide a data rich avenue for investigating the feasibility.

The global findings demonstrated that a relatively small amount, compared to the total number of samples in the entire dataset, of spectral samples and matched geochemistry can be used to successfully train a combined NMF and RFR model to make accurate and quantitative predictions. The dataset used for this study are from a reasonably uniform and non-diverse geology and allowed accurate predictions to be made that extended far beyond the spatial confines of the training and test dataset locations. If the underlying geology was to markedly depart from that of the training and test data used to build the models, then it would require new models to be built that can incorporate such changes.

However, not all the whole-rock entries were modelled well or even able to be modelled. To successful predict quantitative values for a given element requires that the element in question had a broad range. By this it is meant that if an element, such as P or S, are not well represented within the geology and samples then there is, as intuitively expected, nothing to model. In this study several geochemical elements had a small range of values and/or where distributed close to the origin. These represented background values of which larger values were not always present, as was the case with $\mathrm{TiO}_{2}$ and $\mathrm{K}_{2} \mathrm{O}$, and for which the predictive power of the model with these elements was limited. Other elements such as $\mathrm{CaO}$ and $\mathrm{MgO}$ demonstrated bimodal distributions whose range, even though the bulk of the values are scattered accumulated about the origin, allowed a reasonable quantitative prediction to be made. In most cases the RMSE on those elements which were range restricted were still small and can be used confirm that the element is of background quantities.

This aspect was reiterated by producing per-drillcore $\mathrm{R}^{2}$ scores and RMSE values. Those elements that had an extensive range, such as $\mathrm{Fe}$ and $\mathrm{SiO}_{2}$, produced per-hole high $\mathrm{R}^{2}$ scores and small RMSE values. On the contrary, and specifically for those elements that were range constrained, poor $\mathrm{R}^{2}$ scores (while still producing low RMSE in most cases) result. However, when drillcore are encountered with an extended range the individual $\mathrm{R}^{2}$ increases and the RMSE also slightly increase.

While this may seem like an obvious result it is worth noting and bearing in mind that if one trains and validates a model and applies it, for example to a single drillcore, the returned result, if it was compared later to measured values for that same single drillcore, may appear to be poor. In other words, producing an $\mathrm{R}^{2}$ score on the singular drillcore should not be used as an indicator of model performance.

Additionally, the use of a RFR model in this case has proven to be successful but it has limitations that may necessitate the retraining of the model at future dates. While the RFR is robust it does not extrapolate and hence cannot return predictions beyond the largest and smallest values used to train the model. Thus, if the initial data used to train the model is a subset of a greater range then the model would need retraining to account for the extended range. Indicators this may be needed are results being returned that are consistently at the extent of training data's range.

In this study the spectral data cover a comprehensive wavelength range that might not be considered typical. However, the principle applied should be viable for reduced spectral ranges such as those encountered by the HyLogger only or by FTIR only. It is expected that a reduced range, and hence a lack of absorptions features that are representative of various elements, may lead to a reduction in the overall accuracy of the model depending on the element sought and the spectral range considered. For example, attempting to quantify $\mathrm{SiO}_{2}$ from the VNIR/SWIR spectral range may prove to be extremely difficult due to the lack of absorption features associated with $\mathrm{SiO} 2$ in that spectral range. Future work will test this hypothesis by constraining the data to reduced ranges to evaluate the impact on the regressions. 
In summary a viable method of predicting several whole rock geochemistry parameters from spectral measurements of pulps has been defined and validated against a much larger spatially distributed dataset. Of the 8 parameters modelled, 4 show exceptional promise and have validation $\mathrm{R}^{2}$ scores greater than 0.8 and RMSE in the low single digit range. Of the other 4 parameters the $\mathrm{R}^{2}$ were less however the RMSE scores possibly still acceptable. The proposed method could be used to return a quick turnaround of potential downhole distributions and might be used to better spend an analysis budget. Namely, by highlighting spatial regions prior to laboratory based whole rock analysis more focus, namely through the laboratory analysis, can be made of those areas deemed to be of economic importance. Conversely areas identified by the proposed method of having no economic importance might be subject to laboratory analysis at a reduced sampling space.

Author Contributions: Conceptualization, A.R.; methodology, A.R.; software,A.R.; validation, A.R., C.L.; formal analysis, A.R, C.L..; writing-original draft preparation, A.R..; writing-review and editing, A.R., C.L.; All authors have read and agreed to the published version of the manuscript.

Funding: This research received no external funding.

Data Availability Statement: In this section, please provide details regarding where data supporting reported results can be found, including links to publicly archived datasets analyzed or generated during the study. Please refer to suggested Data Availability Statements in section "MDPI Research Data Policies" at https://www.mdpi.com/ethics. You might choose to exclude this statement if the study did not report any data.

Conflicts of Interest: The authors declare no conflict of interest.

\section{References}

1. Yamaguchi, Y.; Naito, C. Spectral Indices for Lithologic Discrimination and Mapping by Using the ASTER SWIR Bands. Int. J. Remote Sens. 2003, 24, 4311-4323.

2. Duke, E.F. Near Infrared Spectra of Muscovite, Tschermak Substitution, and Metamorphic Reaction Progress: Implications for Remote Sensing. Geology 1994, 22, 621-624.

3. Hewson, R.D.; Cudahy, T.J.; Caccetta, M.; Rodger, A.; Jones, M.; Ong, C. Advances in Hyperspectral Processing for Province-and Continental-Wide Mineral Mapping. In Proceedings of the 2009 IEEE International Geoscience and Remote Sensing Symposium; IEEE, 2009; Vol. 4, p. IV-701.

4. Cudahy, T.; Jones, M.; Thomas, M.; Laukamp, C.; Caccetta, M.; Hewson, R.; Verrall, M.; Hacket, A.; Rodger, A. Mineral Mapping Queensland: Iron Oxide Copper Gold (IOCG) Mineral System Case History, Starra, Mount Isa Inlier.; Australasian Institute of Mining and Metallurgy: Gold Coast, Queensland, Australia, November 25 2008; pp. 153-160.

5. Cudahy, T.; Jones, M.; Thomas, M.; Laukamp, C.; Caccetta, M.; Hewson, R.; Rodger, A.; Verrall, M. Next Generation Mineral Mapping: Queensland Airborne HyMap and Satellite ASTER Surveys 2006-2008; Perth, 2008; p. 152;.

6. Wells, M.; Laukamp, C.; Hancock, E. Reflectance Spectroscopic Characterisation of Mineral Alteration Footprints Associated with Sediment-Hosted Gold Mineralisation at Mt Olympus (Ashburton Basin, Western Australia). Aust. J. Earth Sci. 2016, 63, 987-1002, doi:10.1080/08120099.2016.1264476.

7. Green, D.; Schodlok, M. Characterisation of Carbonate Minerals from Hyperspectral TIR Scanning Using Features at 14000 and $11300 \mathrm{Nm}$. Aust. J. Earth Sci. 2016, 63, 951-957.

8. Laukamp, C.; Cudahy, T.; Thomas, M.; Jones, M.; Cleverley, J.S.; Oliver, N.H.S. Hydrothermal Mineral Alteration Patterns in the Mount Isa Inlier Revealed by Airborne Hyperspectral Data. Aust. J. Earth Sci. 2011, 58, 917-936.

9. Laukamp, C.; Termin, K.A.; Pejcic, B.; Haest, M.; Cudahy, T. Vibrational Spectroscopy of Calcic AmphibolesApplications for Exploration and Mining. Eur. J. Mineral. 2012, 24, 863-878. 
10. Haest, M.; Cudahy, T.; Laukamp, C.; Gregory, S. Quantitative Mineralogy from Infrared Spectroscopic Data. I. Validation of Mineral Abundance and Composition Scripts at the Rocklea Channel Iron Deposit in Western Australia. Econ. Geol. 2012, 107, 209-228, doi:10.2113/econgeo.107.2.209.

11. Agar, B.; Coulter, D. Remote Sensing for Mineral Exploration-A Decade Perspective 1997-2007. In Proceedings of the Proceedings of Exploration; 2007; Vol. 7, pp. 109-136.

12. Roache, T.J.; Walshe, J.L.; Huntington, J.F.; Quigley, M.A.; Yang, K.; Bil, B.W.; Blake, K.L.; Hyvärinen, T. EpidoteClinozoisite as a Hyperspectral Tool in Exploration for Archean Gold. Aust. J. Earth Sci. 2011, 58, 813-822, doi:10.1080/08120099.2011.608170.

13. Geladi, P.; Kowalski, B.R. Partial Least-Squares Regression: A Tutorial. Anal. Chim. Acta 1986, 185, 1-17.

14. Hecker, C.; Dilles, J.H.; van der Meijde, M.; van der Meer, F.D. Thermal Infrared Spectroscopy and Partial Least Squares Regression to Determine Mineral Modes of Granitoid Rocks. Geochem. Geophys. Geosystems $2012,13$.

15. Kun, W.; Keyan, X.; Nan, L.; Yuan, C.; Shengmiao, L. Application of Partial Least Squares Regression for Identifying Multivariate Geochemical Anomalies in Stream Sediment Data from Northwestern Hunan, China. Geochem. Explor. Environ. Anal. 2017, 17, 217-230.

16. Haaland, D.M.; Thomas, E.V. Partial Least-Squares Methods for Spectral Analyses. 1. Relation to Other Quantitative Calibration Methods and the Extraction of Qualitative Information. Anal. Chem. 1988, 60, 1193-1202, doi:10.1021/ac00162a020.

17. Ritz, M.; Vaculikova, L.; Plevová, E.; Matỳsek, D.; Mališ, J. Determination of Chlorite, Muscovite, Albite and Quartz in Claystones and Clay Shales by Infrared Spectroscopy and Partial Least-Squares Regression. 2012.

18. Breiman, L. Random Forests. Mach. Learn. 2001, 1, 5-32, doi:10.1023/A:1010933404324.

19. Kuhn, S.; Cracknell, M.J.; Reading, A.M. Lithologic Mapping Using Random Forests Applied to Geophysical and Remote-Sensing Data: A Demonstration Study from the Eastern Goldfields of Australia. GEOPHYSICS 2018, 83, B183-B193, doi:10.1190/geo2017-0590.1.

20. Kumar, A.S.; Keerthi, V.; Manjunath, A.S.; van der Werff, H.; van der Meer, F. Hyperspectral Image Classification by a Variable Interval Spectral Average and Spectral Curve Matching Combined Algorithm. Int. J. Appl. Earth Obs. Geoinformation 2010, 12, 261-269.

21. McKay, G.; Harris, J.R. Comparison of the Data-Driven Random Forests Model and a Knowledge-Driven Method for Mineral Prospectivity Mapping: A Case Study for Gold Deposits Around the Huritz Group and Nueltin Suite, Nunavut, Canada. Nat. Resour. Res. 2016, 25, 125-143, doi:10.1007/s11053-015-9274-z.

22. Kirkwood, C.; Cave, M.; Beamish, D.; Grebby, S.; Ferreira, A. A Machine Learning Approach to Geochemical Mapping. J. Geochem. Explor. 2016, 167, 49-61, doi:10.1016/j.gexplo.2016.05.003.

23. Tuşa, L.; Khodadadzadeh, M.; Contreras, C.; Rafiezadeh Shahi, K.; Fuchs, M.; Gloaguen, R.; Gutzmer, J. Drill-Core Mineral Abundance Estimation Using Hyperspectral and High-Resolution Mineralogical Data. Remote Sens. 2020, 12, 1218, doi:10.3390/rs12071218.

24. Smith, B.R.; Huntington, J.F. National Virtual Core Library NTGS Node: HyLogger 2-7. 2010.

25. Schodlok, M.C.; Whitbourn, L.; Huntington, J.; Mason, P.; Green, A.; Berman, M.; Coward, D.; Connor, P.; Wright, W.; Jolivet, M. HyLogger-3, a Visible to Shortwave and Thermal Infrared Reflectance Spectrometer System for Drill Core Logging: Functional Description. Aust. J. Earth Sci. 2016, 63, 929-940.

26. Cracknell, M.J.; Jansen, N.H. National Virtual Core Library HyLogging Data and Ni-Co Laterites: A Mineralogical Model for Resource Exploration, Extraction and Remediation. Aust. J. Earth Sci. 2016, 63, 1053-1067.

27. Lee, D.D.; Seung, H.S. Learning the Parts of Objects by Non-Negative Matrix Factorization. Nature 1999, 401, 788791.

28. Pedregosa, F.; Varoquaux, G.; Gramfort, A.; Michel, V.; Thirion, B.; Grisel, O.; Blondel, M.; Prettenhofer, P.; Weiss, R.; Dubourg, V. Scikit-Learn: Machine Learning in Python. J. Mach. Learn. Res. 2011, 12, 2825-2830. 
29. Lee, D.D.; Seung, H.S. Algorithms for Non-Negative Matrix Factorization. In Advances in Neural Information Processing Systems 13; Leen, T.K., Dietterich, T.G., Tresp, V., Eds.; MIT Press, 2001; pp. 556-562.

30. Cichocki, A.; Phan, A.-H. Fast Local Algorithms for Large Scale Nonnegative Matrix and Tensor Factorizations. IEICE Trans. Fundam. Electron. Commun. Comput. Sci. 2009, 92, 708-721.

31. Févotte, C.; Idier, J. Algorithms for Nonnegative Matrix Factorization with the $\beta$-Divergence. Neural Comput. 2011, 23, 2421-2456.

32. Du, B.; Wang, S.; Wang, N.; Zhang, L.; Tao, D.; Zhang, L. Hyperspectral Signal Unmixing Based on Constrained Non-Negative Matrix Factorization Approach. Neurocomputing 2016, 204, 153-161.

33. Liu, R.; Du, B.; Zhang, L. Hyperspectral Unmixing via Double Abundance Characteristics Constraints Based NMF. Remote Sens. 2016, 8, 464, doi:10.3390/rs8060464.

34. Hamza, A.B.; Brady, D.J. Reconstruction of Reflectance Spectra Using Robust Nonnegative Matrix Factorization. IEEE Trans. Signal Process. 2006, 54, 3637-3642, doi:10.1109/TSP.2006.879282.

35. Bao, W.; Li, Q.; Xin, L.; Qu, K. Hyperspectral Unmixing Algorithm Based on Nonnegative Matrix Factorization. In Proceedings of the 2016 IEEE International Geoscience and Remote Sensing Symposium (IGARSS); July 2016; pp. 6982-6985.

36. Févotte, C.; Dobigeon, N. Nonlinear Hyperspectral Unmixing with Robust Nonnegative Matrix Factorization. IEEE Trans. Image Process. 2015, 24, 4810-4819.

37. Berry, M.W.; Browne, M.; Langville, A.N.; Pauca, V.P.; Plemmons, R.J. Algorithms and Applications for Approximate Nonnegative Matrix Factorization. Comput. Stat. Data Anal. 2007, 52, 155-173.

38. Probst, P.; Boulesteix, A.-L. To Tune or Not to Tune the Number of Trees in Random Forest? ArXiv170505654 Cs Stat 2017.

39. Scheinost, A.C. Use and Limitations of Second-Derivative Diffuse Reflectance Spectroscopy in the Visible to NearInfrared Range to Identify and Quantify Fe Oxide Minerals in Soils. Clays Clay Miner. 1998, 46, 528-536, doi:10.1346/CCMN.1998.0460506.

40. Frost, R.L.; Johansson, U. Combination Bands in the Infrared Spectroscopy of Kaolins - a DRIFT Spectroscopic Study. Clays Clay Miner. 1998, 46, 466-477.

41. Gaffey, S.J. Spectral Reflectance of Carbonate Minerals in the Visible and near Infrared (0.35-2.55 Microns); Calcite, Aragonite, and Dolomite. Am. Mineral. 1986, 71, 151-162.

42. Spitzer, W.G.; Kleinman, D.A. Infrared Lattice Bands of Quartz. Phys. Rev. 1961, 121, 1324-1335, doi:10.1103/PhysRev.121.1324.

43. Lippincott, E.R.; Van Valkenburg, A.; Weir, C.E.; Bunting, E. Infrared Studies on Polymorphs of Silicon Dioxide and Germanium Dioxide. J. Res. Natl. Bur. Stand. 1958, 61, 61-70.

44. Madejová, J.; Komadel, P. BASELINE STUDIES OF THE CLAY MINERALS SOCIETY SOURCE CLAYS: INFRARED METHODS. Clays Clay Miner. 2001, 49, 410-432.

45. Ruan, H.D.; Frost, R.L.; Kloprogge, J.T. Comparison of Raman Spectra in Characterizing Gibbsite, Bayerite, Diaspore and Boehmite. J. Raman Spectrosc. 2001, 32, 745-750.

46. Ramanaidou, E.R.; Wells, M.; Belton, D.X.; Verrall, M.; Ryan, C. Mineralogical and Microchemical Methods for the Characterization of High-Grade Banded Iron Formation-Derived Iron Ore. 2008.

47. Ramanaidou, E.; Wells, M.; Lau, I.; Laukamp, C. 6 - Characterization of Iron Ore by Visible and Infrared Reflectance and, Raman Spectroscopies. In Iron Ore; Lu, L., Ed.; Woodhead Publishing, 2015; pp. 191-228 ISBN 978-1-78242-156-6.

48. Zaini, N.; Van der Meer, F.; Van der Werff, H. Effect of Grain Size and Mineral Mixing on Carbonate Absorption Features in the SWIR and TIR Wavelength Regions. Remote Sens. 2012, 4, 987-1003, doi:10.3390/rs4040987. 
49. Rowlands, N.; Neville, R.A. Calcite and Dolomite Discrimination Using Airborne SWIR Imaging Spectrometer Data. In Proceedings of the Imaging Spectrometry II; International Society for Optics and Photonics, November 13 1996; Vol. 2819, pp. 36-44.

50. Zaini, N.; Van der Meer, F.; Van der Werff, H. Determination of Carbonate Rock Chemistry Using LaboratoryBased Hyperspectral Imagery. Remote Sens. 2014, 6, 4149-4172, doi:10.3390/rs6054149.

51. Bishop, J.L. The Visible and Infrared Spectral Properties of Jarosite and Alunite. Am. Mineral. 2005, 90, 1100-1107, doi:10.2138/am.2005.1700. 